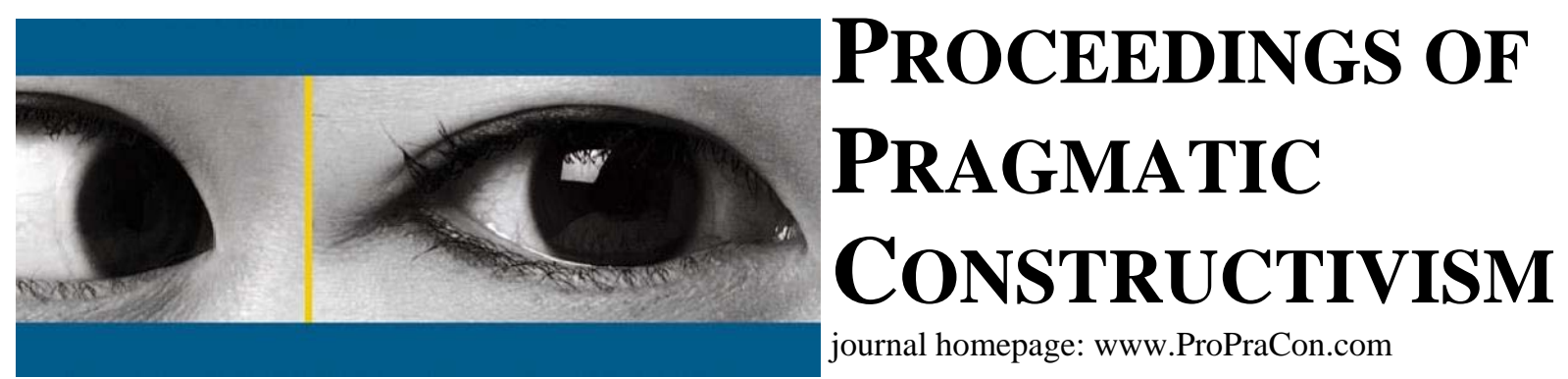

\title{
Being and doing in organizations: agents, actors or persons?
}

\section{Sue Llewellyn}

Professor of Accountability and Management Control and Director of Herbert Simon Institute Manchester Business School

Booth Street West, Manchester M15 6PB, UK; sue.llewellyn@mbs.ac.uk

\begin{abstract}
It is the aim of this article to understand what it means to be an agent , actor or person in an organization using theoretical arguments from Giddens and Archer.
\end{abstract}

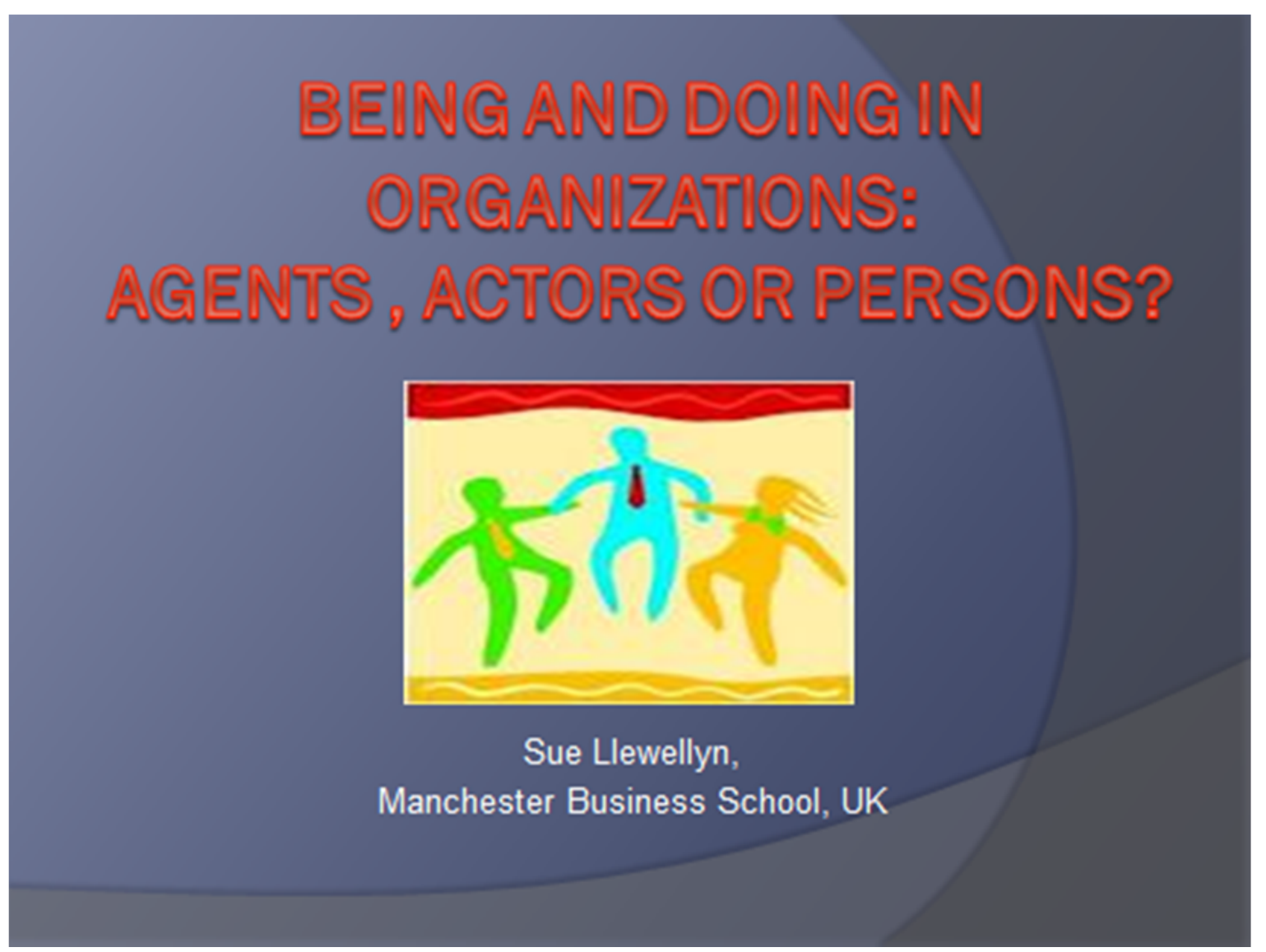




\section{Aim of the presentation}

To understanding what it means to be an agent, actor or person in an organization using theoretical arguments from Giddens and Archer. This is important because:

Most human purposes are achieved through human projects in organizations.

The constitution of the agent/actor/person is currently not well understood, usually being equated with a psychological perspective.

An alternative view of an organization is that it is an arena of the accomplishment of a multiplicity of human projects.

\section{What is an Agent?}

An agent is a perpetrator -person who does things. She does not necessarily intend to do them.

An agent has the capability to pursue a project; agents organize to execute projects-as "being organized" with others has "emergent powers" to extend and/or increase their capabilities as agents.

Giddens and Archer are agreed with respect to theoretical views on agents as people who do things and have projects 


\section{What is an Actor?}

For Giddens, agent and actor are synonymous

For Archer an actor is a person with a role (in an organization)

Giddens and Archer disagree on actors in so far as Archer differentiates actors from agents- all actors are agents but not all agents are actors

\section{What is a Person?}

For Giddens, a person is someone who can articulate reasons for their conduct and is able to elaborate on them (including lying about them).

For Archer, a person is someone who can personify a role rather than merely animating it.

On personhood they do not disagree but stress different aspects of being a person 


\section{Archer's View of the Agent/Actor/Person}

Dialectical life long account- captures the interplay between personal identity (self and primary agent) and social identity (corporate agent and actor).

Primary agency is involuntary and primary agents lack any say in structural and cultural re-modelling

Corporate agents are active and organized Not all corporate agents are actors

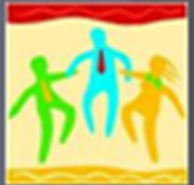

\section{Giddens' View of the Agent/Actor/Person}

Agents/actors/persons reflexively monitor self, others and the context of action.

Agents/actors/persons can rationalize- i.e. articulate the theoretical grounds of their action Agents/actors/persons'motivation refers to the potential for action rather than the action itself The knowledgeable agent /actor/person exhibits three forms of consciousness: discursive, practical and unconscious.

"Structure" is not external to agents/actors/persons-as memory traces and as instantiated in practices-it is part of their constitution.

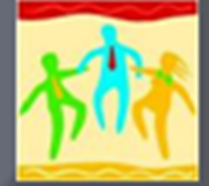




\section{Archer and Giddens on Being and Doing}

Archer's focus is on

being as in agential

positioning and

organizational role

Corporate agent and

corporate actor are

close to

organizational forms

Better at the "being"

question?
Giddens is focussed

on agential "powers"

Gives a account of the knowledge and powers of agents

Better at the "doing" question?

\section{Concluding Comments:}

the "Why is this important" Question

Even those aspects of organization that appear the most deeply embedded in structures, e.g. rationalization, bureaucratization, globalization were once human projects

Organization is about practical interventions in the world- we need accounts of "that which has to be done"- a purely subjective view of agents/actors/persons cannot suffice.

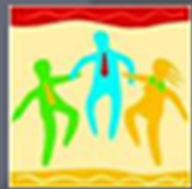

